\title{
Factors associated with compliance to a course of physical exercises for a selected group of primigravida mothers in Sri Lanka
}

\author{
I.N.S. Herath ${ }^{1}$, A. Balasuriya ${ }^{2}$, S. Sivayogan ${ }^{3}$
}

\begin{abstract}
Introduction: The aim of this study was to assess factors associated with compliance to a course of exercises administered for a selected group of primigravida mothers in second trimester.

Methods: This was a descriptive cross sectional and qualitative study performed at a Medical Officer of Health area in Kegalle district. Study population was a group of postnatal mothers who had taken part in the course of exercises from second trimester, for a period of 16 weeks. Sample size was 138 postnatal mothers. Study instruments were a self-administered questionnaire to obtain baseline data, psychological state and compliance to exercises, a diary and an interviewer administered questionnaire for views of husband and household members.
\end{abstract}

Results: There were statistically significant associations between maternal age being less than or equal to 30 years and increase regularity of exercises $(p<0.05)$, levels of education of husbands and the exercise regularity of pregnant mothers $(p<0.05)$ and absence of physical symptoms and increase participation in regular exercises $(p<0.05)$. There was no statistically significant association ( $p>0.05$ ) between psychological distress status at six weeks postpartum and exercise regularity. There was a statistically significant association $(p<0.05)$ between regularity of exercise and reduced presentation of depression at six weeks postpartum. Lethargy $(41 \%)$, tiredness $(20 \%)$, lack of time $(16 \%)$, lack of privacy $(13 \%)$ and absence of husband (11\%) were reasons for not carrying out exercises regularly. Encouragement and motivation by family members (38\%), husband $(33 \%)$ and Public Health Midwife $(27 \%)$ and feeling of good health after doing exercises $(20 \%)$ were the main factors which helped a mother to carry out exercise regularly.

Conclusions: Younger age, absence of physical symptoms and absence of depressive symptoms is significantly associated with regularity of exercises as opposed to irregularity

Key words: antenatal, compliance, exercises, physical, psychological

\section{INTRODUCTION}

Pregnancy is a time of intense physical change and it is associated with a great deal of emotional upheaval in many women. Although motherhood is often a positive and fulfilling experience, for some women it is associated with suffering, ill-health and even death. The safe-motherhood

\footnotetext{
1. Ministry of Health Sri Lanka

2. Faculty of Medicine, General Sir John Kotelawala Defense University

3. Faculty of Medical Sciences, University of Sri Jayewardenepura
}

Correspondence: Dr. I. N. S. Herath

E-mail: nadeejaherath@yahoo.com

Competing interests: None initiative launched in 1987 emphasizes all women to receive not only curative, but preventive measures as well, as they need to be safe and healthy throughout pregnancy and childbirth.

Different countries use different techniques to manage a pain free pregnancy and delivery which includes exercises during pregnancy such as Yoga, breathing exercises, meditation, Lamaze technique, Bradley method, Reiki, Pilates etc. In Sri Lanka, antenatal exercises are offered to pregnant women at some government and private sector hospitals and organizations. Some government hospitals and many field antenatal clinics educate women on the importance of physical exercises during pregnancy.
But, a relevant question is whether the pregnant females would be willing to comply with a course of exercises. Even if they initially complied to exercise, whether they will continue it up to delivery of the baby is doubtful.

Though scarce, some researchers have looked at this question. A USA study revealed that those who have exercised prior to pregnancy continued to do so with a lesser average intensity ${ }^{1}$. Other correlates of physical activity in pregnancy from research were higher level of education, higher level of income, white women, nonsmokers and those who consume high proteins $^{1,2}$. An exploratory analysis of exercise adherence patterns with sedentary pregnant women revealed that women who demonstrated high adherence at the beginning tended to remain that way and vice versa ${ }^{3}$.

Therefore, this study was conducted to determine the extent of compliance to a course of antenatal exercises and to assess the factors associated with compliance of pregnant females.

\section{METHODS}

A descriptivecross sectionalstudy with qualitative components was carried out at the Medical Officer of Health $(\mathrm{MOH})$ area, Galigamuwa in Kegalle district. In an earlier component of this study, an intervention study was conducted to implement a course of antenatal exercises for primigravid mothers from their second trimester (illustration 1). The study population was all the mothers in the intervention arm, exercised for at least 16 weeks. These 138 mothers were recruited at six weeks after delivery.

Data collection was carried out using a self-administered questionnaire to obtain baseline data and compliance to exercises, General Health Questionnaire (GHQ) 30 to assess psychological distress, Edinburgh Postpartum Depression Scale (EPDS) 


\section{Illustration 1}

Exercise guideline for antenatal mothers (which was to be carried out for 16 weeks from second trimester)

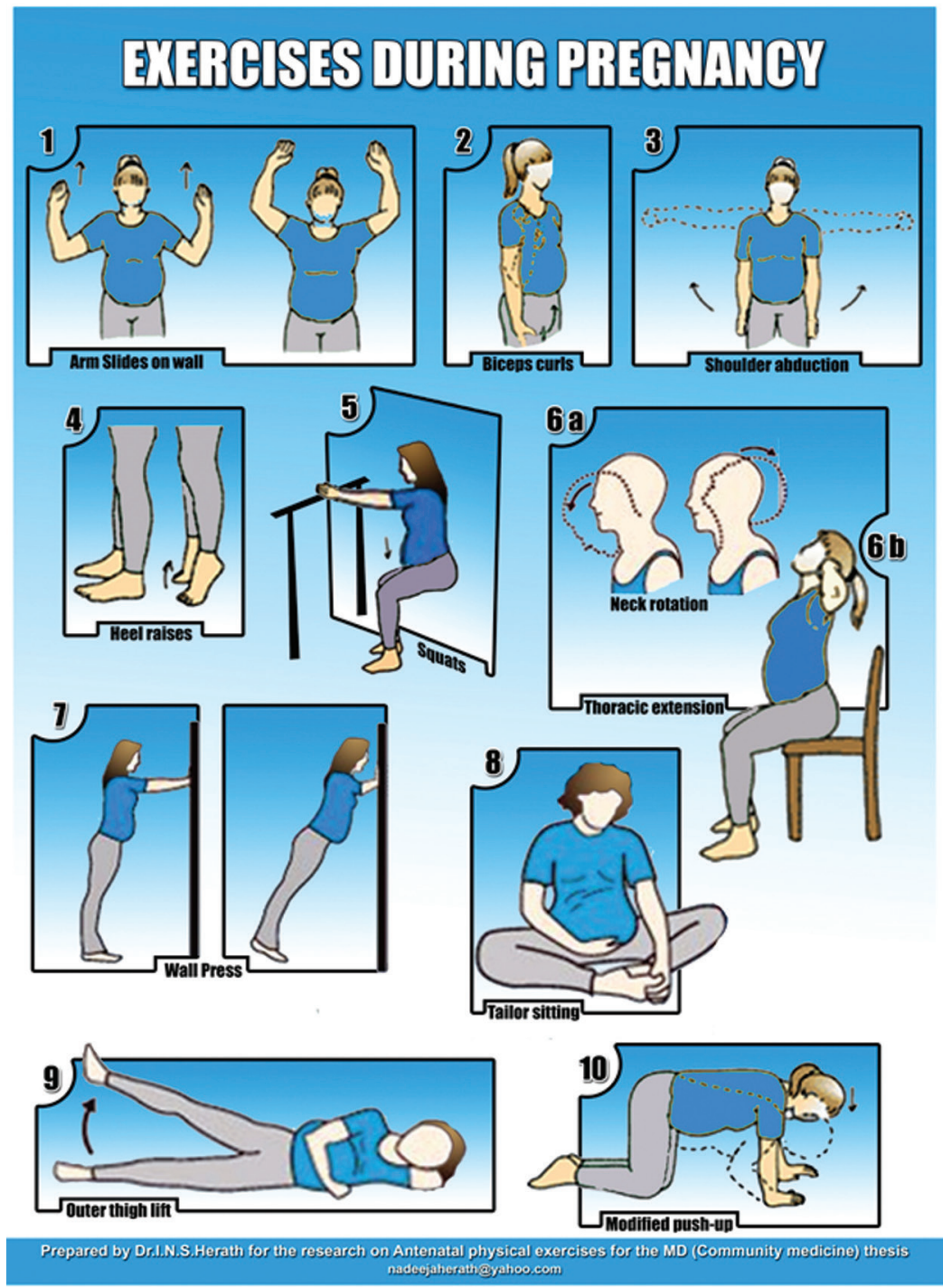

to assess level of depression, an interview guide for views of husbands and other household members (selected randomly) and the diary which was used to record exercise dates and times during pregnancy was scrutinized. Measures like observing the skillfulness of carrying out exercises and asking the mothers to demonstrate an exercise step to see if they had genuinely adhered to exercise schedule regularly had been carried out during the earlier component of the study to assess the accuracy of the entries in the diary.

Ethical clearance was obtained from the Faculty of Medical Sciences, University of Sri Jayawardenapura and administrative clearance was exercises for a pregnant woman. Of the 138 mothers, 71 (51.4\%) had participated in exercises regularly.

Socio-demographic factors were cross tabulated with regularity of exercises in table 1. Regularity of exercises was associated with younger age 30 years and below $\left(\chi^{2}=10.1, p<.05\right)$ and with ethnicity other than Sinhala $\left(\chi^{2}=0.36, p>.05\right)$. In table 2 , regularity of exercises showed a significant association with the educational level of the husband $\left(\chi^{2}=8.98\right)$ and there was an increasing regularity of exercises with decreasing age of the husband though not significant $\left(X^{2}=3.88\right.$, d.f. $=2$, $\mathrm{p}>$.05).

There was no statistically significant difference $\quad(p>0.05) \quad$ with living arrangement of the couple and the exercise regularity in this study (table $3)$.

Nearly $60 \%$ among mothers who had no physical problems had participated in regular exercises whereas it was only about $39 \%$ among those mothers with physical problems. There was a statistically significant association $(p<0.05)$ between the absence of physical problems and increased participation in exercises regularly (table 4).

Among those mothers who were not psychologically distressed (GHQ30 score $\leq 5$ ), more than half had participated in regular exercises (table 5). There was only about $25 \%$ mothers among the psychologically distressed (GHQ-30 score >5) who participated in regular exercises. However, there was no statistically significant association $(p>0.05)$ between psychological distress status at six weeks postpartum and exercise regularity. Similarly, among mothers who were not depressed (EPDS score $\leq 9)$, more than half had participated in regular exercises. Less than 10\% had participated in regular exercises among mothers who were depressed (EPDS score $>9)$. This association of no depression and increased regularity of exercise among six weeks postpartum mothers was statistically significant $(\mathrm{p}<0.05)$.

There were other factors associated with compliance to physical exercises. Lethargic feeling $(41 \%)$ was the main 
Table 1. Regularity of exercises in the antenatal mother by selected socio demographic factors

\begin{tabular}{|c|c|c|c|}
\hline \multirow{2}{*}{$\begin{array}{l}\text { Socio demographic factors of } \\
\text { antenatal mother }\end{array}$} & \multicolumn{2}{|c|}{ Exercises } & \multirow[t]{2}{*}{ Significance } \\
\hline & $\begin{array}{c}\text { Regular } \\
\text { (N=71) } \\
\text { n (\%) }\end{array}$ & $\begin{array}{c}\text { Irregular (N=67) } \\
n(\%)\end{array}$ & \\
\hline \multicolumn{4}{|l|}{ Age group (in years) } \\
\hline Up to 30 & $67(57.8)$ & $49(42.2)$ & \multirow{2}{*}{$\begin{array}{l}* \chi^{2}=10.1 \\
d f=1 \\
p<0.05\end{array}$} \\
\hline$>30$ & $4(18.2)$ & $18(81.8)$ & \\
\hline \multicolumn{4}{|l|}{ Level of education } \\
\hline Up to grade 10 & $7(53.8)$ & $6(46.2)$ & \multirow{2}{*}{$\begin{array}{l}\chi^{2}=0.03 \\
d f=1 \\
p>0.05\end{array}$} \\
\hline Grade $11 \&$ above/ others & $64(51.2)$ & $61(48.8)$ & \\
\hline \multicolumn{4}{|l|}{ Occupation } \\
\hline Employed & $14(48.3)$ & $15(51.7)$ & \multirow{2}{*}{$\begin{array}{l}\chi^{2}=0.15 \\
d f=1 \\
p>0.05\end{array}$} \\
\hline Housewives & $57(52.3)$ & $52(47.7)$ & \\
\hline \multicolumn{4}{|l|}{ Ethnicity } \\
\hline Sinhala & $65(50.4)$ & $64(49.6)$ & \multirow{2}{*}{$\begin{array}{l}{ }^{*} \chi^{2}=0.36 \\
d f=1 \\
p>0.05\end{array}$} \\
\hline Tamil \& Muslim & $6(66.7)$ & $3(33.3)$ & \\
\hline
\end{tabular}

\section{* Yates continuity correction done}

reason given for not carrying out exercises regularly by the mothers in this group. This was followed by tiredness $(20 \%)$ and lack of time $(16 \%)$. These were all intrapersonal factors. The main interpersonal factors were lack of privacy at home $(13 \%)$ and absence of husband (11\%). Beliefs have also contributed to compliance in this study, which is depicted by $1.4 \%$ not exercising on full moon days (table 6).

The main factors which helped a mother to carry out exercise regularly (table 7) were encouragement and motivation by family members $(38 \%)$ and the husband (33\%). The encouragement and motivation by Public Health Midwife (PHM) accounted for about $27 \%$. These were all interpersonal factors whereas the main intrapersonal factor was feeling of good health after doing exercises $(20 \%)$.
When enquired about methods that can be used to improve this exercise course (as perceived by antenatal mothers), about $28 \%$ of mothers felt that myths in society with regard to pregnancy and exercises should be eliminated. $15 \%$ felt that the message of exercises need to be spread among the peer groups and a similar percentage felt that it is necessary to educate and spread the message to other mothers (table 11).

The factors that would increase the participation of more mothers in this type of exercise programmes, according to antenatal mothers, were also elicited (table 12). Many mothers $(38 \%)$ interviewed felt that increasing the knowledge and attitude of mothers with regard to maternal exercises would increase participation of more mothers in this type of exercise programme. This was followed by education about benefits of exercises $(33.3 \%)$ and increasing positive beliefs towards exercises $(23.2 \%)$. About $2 \%$ of the mothers were of the view that mothers who exercise and do not exercise should exchange knowledge/ views.

Interview of selected number of husbands $(\mathrm{N}=45)$ and household members $(\mathrm{N}=20)$, who volunteered to participate in the discussion, was also carried out. About 38\% of husbands feel that their wives tend to complain less when they were engaged in exercises. Some (33.3\%) husbands feel that wives become more active while some $(22.2 \%)$ feel that wives become more cheerful after exercises. However, about $7 \%$ of the husbands say that their wives sometimes complain of aches and pains after exercises. Majority (67\%) of husbands feel that the given exercises course as a whole was not difficult. Whereas $60 \%$ feel that it can be carried out by pregnant mothers very easily. Also, $13 \%$ husbands feel that exercises should be made compulsory.

Enquiry from other household members with regard to the behavior of pregnant mothers when engaging in exercises revealed that, antenatal mothers engaged in household work more after exercises (50\%). Of them, $40 \%$ said the mothers seemed to be happier and 35\% said they complained 
less or not complained of aches and pains at all. Furthermore, majority $(70 \%)$ of the household members feel that exercises should be introduced to all mothers. They are also of the view that exercises are not difficult (60\%).

\section{DISCUSSION}

The participants in this study were postnatal mothers who had delivered their first baby and had taken part in an exercise programme for sixteen weeks during the antenatal period, commencing in their second trimester of pregnancy. Of the 138 females who completed the prescribed period of exercises, $51.4 \%$ had done it regularly. This is satisfactory in comparison to an estimate of $42 \%$ exercising during pregnancy ${ }^{4}$. Socio-demographic data of mothers were obtained in addition to finding out about the feasibility of carrying out an exercise course from the mother. Also, assistance from husband and other family members were assessed.

The diary method used to record exercises was a common method which was used for exercises worldwide ${ }^{5}$ to recall the exercise dates. The success of this method depends on how well it was introduced to the study participants and the frequency of reinforcements.

In this study, regular exercisers were younger and their husbands also were younger (latter was not significant). In contrast, a study analyzing the Danish National Birth cohort and found an increased likelihood of exercise engagement of mothers who were above 25 years of age. However, it had considered all parity levels and therefore it may be due to the fact that those mothers were experienced, and, when mothers were aware of benefits of exercises they tend to continue $\mathrm{it}^{6}$.

When regularity of exercises were considered, there was an increased proportion of mothers with physical problems who had not participated in regular exercises (62\%) which was statistically significant. This was confirmed in a study which found that main perceived barrier for physical activity during pregnancy was intrapersonal health related causes $(52.1 \%)^{7}$.
Table 2. Regularity of exercises by selected socio demographic factors of husband

\begin{tabular}{|c|c|c|c|}
\hline \multirow{2}{*}{$\begin{array}{l}\text { Socio demographic factors of } \\
\text { husband }\end{array}$} & \multicolumn{2}{|c|}{ Exercises } & \multirow[b]{2}{*}{ Significance } \\
\hline & $\begin{array}{l}\text { Regular } \\
(\mathrm{N}=71) \\
\mathrm{n}(\%)\end{array}$ & $\begin{array}{l}\text { Irregular }(\mathrm{N}=67) \\
\mathrm{n}(\%)\end{array}$ & \\
\hline \multicolumn{4}{|l|}{ Age of husband (in years) } \\
\hline Up to 25 & $14(66.7)$ & $7(33.3)$ & $x^{2}=3.88$ \\
\hline 26 to 30 & $35(53.8)$ & $30(46.2)$ & $d f=2$ \\
\hline$\geq 31$ & $22(42.3)$ & $30(57.7)$ & $p>0.05$ \\
\hline \multicolumn{4}{|l|}{ Education } \\
\hline Up to grade 10 & $16(80.0)$ & $4(20.0)$ & $\chi^{2}=8.98$ \\
\hline Grades 11 - 12 & $25(43.1)$ & 33 (56.9) & $d f=3$ \\
\hline Higher Education & $12(54.5)$ & $10(45.5)$ & $p<0.05$ \\
\hline Vocational training & $18(47.4)$ & $20(52.6)$ & \\
\hline \multicolumn{4}{|l|}{ Occupation } \\
\hline Professional & $7(53.8)$ & $6(46.2)$ & $\begin{array}{l}\chi^{2}=2.9 \\
d f=3 \\
p>0.05\end{array}$ \\
\hline $\begin{array}{l}\text { Manager, technician, } \\
\text { clerical, service/sales }\end{array}$ & $18(62.1)$ & $11(37.9)$ & \\
\hline $\begin{array}{l}\text { Agriculture/ fisheries, } \\
\text { crafts/ related trade, } \\
\text { plant/ machine } \\
\text { operator, elementary } \\
\text { occupation }\end{array}$ & $34(51.5)$ & $32(48.5)$ & \\
\hline Armed forces & $12(40.0)$ & $18(60.0)$ & \\
\hline
\end{tabular}

Table 3. Regularity of exercises by the living arrangement of the couple

\begin{tabular}{|c|c|c|c|}
\hline \multirow[t]{2}{*}{ Living arrangement } & \multicolumn{2}{|c|}{ Exercises } & \multirow[t]{2}{*}{ Significance } \\
\hline & $\begin{array}{c}\text { Regular ( } \mathrm{N}=71) \\
\text { n (\%) }\end{array}$ & $\begin{array}{c}\text { Irregular(N=67) } \\
n(\%)\end{array}$ & \\
\hline \multicolumn{4}{|c|}{ Other occupants living in the house } \\
\hline Wife's parents & $18(40.0)$ & $27(60.0)$ & $\chi^{2}=3.53$ \\
\hline Husband's parents & $38(56.7)$ & $29(43.3)$ & $\mathrm{df}=2$ \\
\hline Other & 15 (57.9) & $11(42.1)$ & $p>0.05$ \\
\hline \multicolumn{4}{|c|}{ Relatives/ non relatives other than parents of either party living with couple } \\
\hline Yes & $11(40.7)$ & $16(59.3)$ & $\begin{array}{r}\chi^{2}=1.05 \\
d f=1\end{array}$ \\
\hline No & 60 (54.1) & 51 (45.9) & $p>0.05$ \\
\hline
\end{tabular}

It was found in our study that the reasons for decline of maternal depression was significantly exercises was psychological factors ${ }^{8}$. associated with regularity of exercises. There was no statistically significant Nearly $92 \%$ of mothers who had a association between presence of high EPDS score had not participated psychological distress and regularity in exercises regularly in our study. of exercises in our study.

Another study disclosed that one of 
Table 4. Regularity of exercises by physical problems at six weeks postpartum

\begin{tabular}{|l|r|r|r|}
\hline Physical problems & \multicolumn{2}{|c|}{ Exercises } & \multirow{2}{*}{ Significance } \\
\cline { 2 - 3 } & Regular (N=71) & Irregular (N=67) & \\
\hline Present & $\mathbf{n}(\%)$ & $\mathbf{n}(\%)$ & \\
Absent & $20(38.5)$ & $32(61.5)$ & $\chi^{2}=4.83$, \\
& & & $\mathrm{df}=1$ \\
& $51(59.3)$ & $35(40.7)$ & \\
& & & \\
\hline
\end{tabular}

Table 5. Regularity of exercises by psychological problems at six weeks postpartum

\begin{tabular}{|c|c|c|c|}
\hline \multirow[t]{3}{*}{ psychological problem } & \multicolumn{2}{|c|}{ Exercises } & \multirow[t]{3}{*}{ Significance } \\
\hline & Regular ( $\mathrm{N}=71)$ & Irregular $(\mathrm{N}=67)$ & \\
\hline & n (\%) & $n(\%)$ & \\
\hline \multicolumn{3}{|l|}{ Psychological distress } & \multirow{3}{*}{$\begin{array}{r}x^{2}=2.61 \\
d f=1 \\
p>0.05\end{array}$} \\
\hline Present $(>5)$ & $3(25.0)$ & $9(75.0)$ & \\
\hline Absent $(\leq 5)$ & $68(54.0)$ & $58(46.0)$ & \\
\hline \multicolumn{3}{|l|}{ Depression } & \multirow{3}{*}{$\begin{array}{r}* \chi^{2}=7.98 \\
d f=1 \\
p<0.05\end{array}$} \\
\hline Present $(>9)$ & $1(8.3)$ & $11(91.7)$ & \\
\hline Absent $(\leq 9)$ & $70(55.6)$ & $56(44.4)$ & \\
\hline
\end{tabular}

*Yates continuity correction applied

Table 6. The reasons provided by mothers for not carrying out exercises regularly were given as follows

\begin{tabular}{|lcc|}
\hline The reasons provided for not carrying out exercises regularly & $\begin{array}{c}\text { Number } \\
\text { (N=138) }\end{array}$ & $\begin{array}{c}\text { Percent } \\
\text { (\%) }\end{array}$ \\
\hline Felt lethargic sometimes & 57 & 41.3 \\
Felt tired after coming home from work sometimes & 28 & 20.3 \\
Lack of time sometimes & 22 & 15.9 \\
There were visitors at home/ no privacy & 18 & 13.0 \\
Husband was not at home & 15 & 10.9 \\
Came home late & 05 & 3.6 \\
Lack of room in the house for exercises sometimes & 03 & 2.2 \\
Forbidden to exercise on some days (full moon days) & 02 & 1.4 \\
Exercise uncomfortable in latter part of pregnancy & 02 & 1.4 \\
Had to go visiting sometimes & 01 & 0.7 \\
\hline
\end{tabular}

Main reasons for not carrying out exercises regularly were intrapersonal and the main factors which helped a mother to carry out exercise regularly were mainly interpersonal. This highlights the importance of getting the husband and other family members involved in the activity from the planning stage in early pregnancy. A Canadian study also found that family support was very much more important when an individual was exercising according to guidelines set out by a health professional ${ }^{9}$. Participants in our study valued the encouragement and motivation given by the area Public Health Midwife. This can be promoted by the hospital based health professionals through the strategy of reorienting health services in the concept of health promotion.

When compliance to exercises was enquired from the mothers in our study, we found that lethargy (41\%), maternal tiredness (20\%), being too busy $(15.9 \%)$, exercise being uncomfortable during the latter part of pregnancy and safety concerns $(1.4 \%)$ and many other factors played an important role for not carrying out exercises regularly. These were similar to the findings of Duncombe and others in which they described the factors which reduced the amount and intensity of exercises over the course of pregnancy ${ }^{10}$. Similar findings of health and non-health related factors were obtained by others studying barriers to physical activity among pregnant women ${ }^{7,11}$.

More than two-third of the mothers did not encounter any problems while exercising and there were many benefits of exercising as felt by the women. These can be further studied as to their scientific basis and used in motivating pregnant females for exercising during pregnancy. In addition, their suggestions in tables 11 and 12 can be incorporated in popularizing the culture of antenatal exercises among pregnant females 
Table 7. The factors which helped the antenatal mothers carry out exercises regularly were given as follows

\begin{tabular}{|c|c|c|}
\hline The factors which helped the antenatal mothers carry out exercises regularly & $\begin{array}{l}\text { Number } \\
(\mathrm{N}=138)\end{array}$ & $\begin{array}{c}\text { Percent } \\
\text { (\%) }\end{array}$ \\
\hline Encouragement and motivation by family members - mother/father/in-laws/sister etc. & 53 & 38.4 \\
\hline Encouragement and motivation by husband & 45 & 32.6 \\
\hline Encouragement and motivation by PHM & 37 & 26.8 \\
\hline Feeling of good health after doing exercises & 28 & 20.3 \\
\hline Praise of others & 19 & 13.8 \\
\hline Keen interest for exercises & 12 & 8.7 \\
\hline A relaxed mind set & 03 & 2.2 \\
\hline Less work as mother/mother in law did most of the work at home & 02 & 1.4 \\
\hline
\end{tabular}

Table 8. The methods used by antenatal mother to cope with difficulties encountered while carrying out exercises were as follows

\begin{tabular}{|l|c|c|}
\hline The methods used by antenatal mother to cope with difficulties encountered while carrying out \\
exercises & $\begin{array}{c}\text { Number } \\
\text { (N=138) }\end{array}$ & $\begin{array}{c}\text { Percent } \\
\text { (\%) }\end{array}$ \\
\hline Have a flexible time for exercises - did not have a fixed time & 27 & 19.6 \\
Weekly pre schedule a time period for the exercises & 24 & 23 \\
Take breaks in between exercises without doing daily & 20 & 17.4 \\
After coming from work rest for a while before engaging in exercises & 18 & 16.7 \\
Ask husband to remind about exercises & 13 & 13.0 \\
Reduce speed of exercises & 11 & 9.4 \\
Carry out exercises during holidays & 09 & 8.0 \\
Stop difficult exercises \& carry out only easy exercises & 08 & 6.5 \\
Ask husband to join in the exercises & 07 & 5.8 \\
Arranged a separate area in the house for exercises & 06 & 5.1 \\
Engaged in exercises when visitors/ house members were not around; so did not felt ashamed & 04 & 4.3 \\
Do the exercises early in the morning & 2.9 \\
\hline
\end{tabular}

Table 9. The problems faced by antenatal mother while doing exercises were given as follows

\begin{tabular}{|l|c|c|}
\hline The problems faced by antenatal mother while doing exercises & $\begin{array}{c}\text { Number } \\
\text { (N=138) }\end{array}$ & $\begin{array}{r}\text { Percent } \\
\text { (\%) }\end{array}$ \\
\hline No problems & 96 & 69.6 \\
Uncomfortable feeling & 19 & 13.8 \\
Non-specific pain & 05 & 10.1 \\
Lower back ache & 03 & 3.6 \\
Lower abdominal pain & 02 & 2.2 \\
Pain in the legs & 02 & 1.4 \\
Tiredness & 01 \\
Pain in the wrists & 0.7 \\
\hline
\end{tabular}


Table 10 The benefits perceived by mothers by engaging in regular exercises

\begin{tabular}{|lcc|}
\hline The benefits perceived by mothers by engaging in & Number & Percent \\
regular exercises & (N=138) & (\%) \\
\hline Feel good & 47 & 34.1 \\
Keep up good physical health & 32 & 23.2 \\
Improve mental health of the mother & 28 & 20.3 \\
Maintain the body figure after pregnancy & 27 & 19.6 \\
Gain self confidence & 22 & 15.9 \\
Feel less fatigued & 21 & 15.2 \\
Reduce body aches and pains & 16 & 11.6 \\
Made mother and baby healthy & 12 & 8.7 \\
Improve wound healing & 09 & 6.5 \\
Delivery of baby was easy & 06 & 4.3 \\
Does not become obese & 05 & 3.6 \\
Can engage in all household work as usual & 03 & 2.2 \\
Burn out excess fat & 02 & 1.4 \\
Breathing becomes easy & 01 & 0.7 \\
\hline
\end{tabular}

Table 11. Methods that can be used to improve this exercise course as perceived by antenatal mothers were given as follows

\begin{tabular}{|l|c|c|}
\hline $\begin{array}{l}\text { Methods that can be used to improve this exercise course as } \\
\text { perceived by antenatal mothers }\end{array}$ & $\begin{array}{c}\text { Number } \\
\text { (N=138) }\end{array}$ & Percent \\
\hline Myths in society with regard to pregnancy \& exercises should & 38 & 27.5 \\
be eliminated & 21 & 15.2 \\
Spread the message of exercises among peer groups & 20 & 14.5 \\
Educate and spread the news of exercises to other mothers as & & \\
much as possible & 18 & 13.0 \\
Show lively colourful pictures to demonstrate exercises & 18 & 13.0 \\
Should educate all family members with regard to exercises & 17 & 12.3 \\
Make husband participate in exercise training compulsory & 08 & 5.8 \\
Demonstrate how to carry out these exercises using a pregnant & & \\
mother & 02 & 1.4 \\
Teach the exercises step by step & 01 & 0.7 \\
Introduce less difficult exercises & & \\
\hline
\end{tabular}

in all strata of the society by creating supportive environment under the concept of health promotion.

With regard to the limitations of the study, exercises carried out by the participants were recorded in a diary provided to them in the intervention study. There may have been issues on the authenticity of the entries. Also, this study was based on the 138 females who completed the prescribed course of exercises. If the females in the control arm of the intervention study and those who did not complete the course of exercises in the intervention arm were studied, that could have been more informative.

\section{CONCLUSIONS AND RECOMMENDATIONS}

It is concluded that younger age, absence of physical symptoms and absence of depressive symptoms is significantly associated with regularity of exercises as opposed to irregularity. It is important to get the husband and other family members and also the area Public Health Midwife involved from the planning stage in prescribing antenatal exercises by the health professional to overcome the barriers which were mainly intrapersonal. The experience and opinion of the study participants can be used in motivating pregnant females for exercising during pregnancy.

Further research is recommended among non-compliant females of antenatal exercises to verify the findings of this study.

Introduction of an intervention or a national programme like this set of exercises during pregnancy should be accompanied by strategies to increase compliance. 
Table 12. Factors that would increase the participation of more mothers in this type of exercise programmes, as perceived by antenatal mothers were given as follows

\begin{tabular}{|l|r|r|}
\hline $\begin{array}{l}\text { Factors that would increase the participation of more mothers in this type of exercise } \\
\text { programmes, as perceived by antenatal mothers }\end{array}$ & $\begin{array}{r}\text { Number } \\
\text { (N=138) }\end{array}$ & 52 \\
\hline Increase knowledge and attitude of mothers with regard to maternal exercises & 46 \\
Educate mothers about the benefits of exercises & 32 \\
Increase positive beliefs towards exercises & 19 \\
Educate the elders who are living with the mothers & 12 \\
Should introduce this to all mothers alike to improve participation & 06 \\
Educate mothers on clinic days & 03 \\
Exchange knowledge among mothers who exercise \& do not exercise & 23.2 \\
Inform the VOOG in the area and get their support as well & 01 & 8.7 \\
\hline
\end{tabular}

\section{REFERENCES}

1. Yeo, S., Cisewski, J., Lock, E.F. and Marron, J.S. (2010). Exploratory analysis of exercise adherence patterns with sedentary pregnant women. Nursing Research, 59 (4), 280 - 287.

2. Ning, Y., Williams, M.A., Dempsey, J.C., Sorensen, T.K., Frederick, I.O. and Luthy, D.A. (2003). Correlates of recreational physical activity in early pregnancy. Journal of Maternal-Fetal and Neonatal Medicine, 13 (6), 385-393.

3. Chasan-Taber, L., Schmidt, M.D., Pekow, P., Sternfeld, B., Manson, J. and Markenson, G. (2007). Correlates of physical activity in pregnancy among Latina women. Journal of Maternal Child Health, 11(4), $353-363$.

4. Haobijam, J., Sharma, U. and David, S. (2010). An exploratory study to assess the family support and its effect on outcome of pregnancy in terms of maternal and neonatal health in a selected hospital, Ludhiana Punjab. Nursing and Midwifery research journal, 6 (4), 137 - 145.

5. Diary. (2015). Wikipedia. Retrieved 12 February, 2015, from http://en.wikipedia. org/wiki/Diary.

6. Carron, A.V., Hausenblas, H.A. and Mack, D. (1996). Social influence and exercise: A Meta-Analysis. Journal of sport \& exercise psychology, 18, 1-16.

7. Clarke, P.E. and Gross, H. (2004). Women's behavior, beliefs and information sources about physical exercise in pregnancy. Midwifery, 20 (2), $133-141$

8. Juhl, M., Madsen, M., Andersen, A.M.N., Andersen, P.K. and Olsen, J. (2010). Distribution and predictors of exercise habits among pregnant women in the Danish National Birth Cohort. Scandinavian journal of medicine and science in sports, 22 (1), 128 - 138. doi:10.1111j.1600-0838.2010.01125.x.

9. Evenson, K.R., Moos, M., Carrier, K. and Siega-Riz, A.M. (2009). Perceived barriers to physical, activity among pregnant women. Maternal Child Health journal, 13(3), $364-375$.

10. Duncombe, D., Wertheim, E.H., Skouteris, H., Paxton, S.J. and Kelly, L. (2009). Factors related to exercise over the course of pregnancy including women's beliefs about the safety of exercise during pregnancy. Midwifery, 25 (4), 430 - 438.

11. Ribeiro, C.P. and Milanez, H. (2011). Knowledge, attitude and practice of women in Campinas, São Paulo, Brazil with respect to physical exercise in pregnancy: a descriptive study. Reproductive Health, 8 (31).

12. American College of Obstetricians and Gynaecologists. (2002). Exercise during pregnancy and the postpartum period, Committee Opinion No.267. Washington DC 20090-6920: American College of Obstetricians and Gynaecologists.

13. Artal, R. and O'Toole, M. (2003). Guidelines of the American College of Obstetricians and Gynecologists for exercise during pregnancy and the postpartum period. British Journal of Sports Medicine,37,6-12.

14. Family Health Bureau. (2011a). Exercise during pregnancy and the postpartum period. Colombo: Ministry of Health Sri Lanka.

15. Family Health Bureau. (2011b). Maternal care package, A guide to field healthcare workers. Colombo: Ministry of Health Sri Lanka. 